\title{
A Primeira Comunicação de Röntgen sobre um novo tipo de Radiação
}

\author{
ECKARD MACHERAUCH E HANS NEFF1,2*
}

Wilhelm Conrad Röntgen nasceu em 27 de Março de 1845 em Lennep, na "Bergischen Land". Cinquenta anos mais tarde era Professor de Física Experimental na Faculdade de Filosofia da Universidade Julius-Maximilian de Würzburg e Director do Instituto de Física, quando, no dia 8 de Novembro de 1895 , ao realizar experiências num tubo em vácuo, descobriu "um novo tipo de radiação" após a análise sistemática duma observação casual. A Figura 1 mostra uma fotografia original do equipamento experimental, então disponível no Instituto de Física de Würzburg. A 28 de Dezembro de 1895, submeteu ao Secretariado da Sociedade de Física Médica em Würtzburg, uma "comunicação preliminar" manuscrita, cuja primeira página está reproduzida na Figura 2. Resumia em 17 capítulos quase todas as observações que haviam sido realizadas nas semanas anteriores, e, ainda no "final de 1895", foi publicada nas Actas da Sociedade. No capítulo 2 , fala-se de um "agente" que "se encontra no estado de produzir uma viva fluorescência", e no capítulo 3. este agente é classificado como "radiação", em relação ao qual Röntgen descreve, como explicação em nota de rodapé:

“para abreviar, pretendo utilizar a expressão radiação $\mathrm{e}$, de modo a distinguir de outros tipos, o nome de radiação-X."

Logo no dia de Ano Novo de 1896, Röntgen enviou a colegas separatas desta notável comunicação, a que juntou cópias de algumas fotografias que havia obtido com a recém-descoberta radiação.

A notícia das observações de Röntgen espalhou-se muito rápidamente para a época de então. A nível mundial foi uma sensação científica, tendo encontrado uma repercursão fora do normal no público internacional. Logo a 4 de Janeiro de 1896 , por ocasião do cinquentenário da Sociedade de Física de Berlim, foi discutida em pormenor a comunicação de Röntgen, bem como as suas fotografias. Um dia mais tarde o público em Viena foi informado da "sensacional descoberta" através do jornal

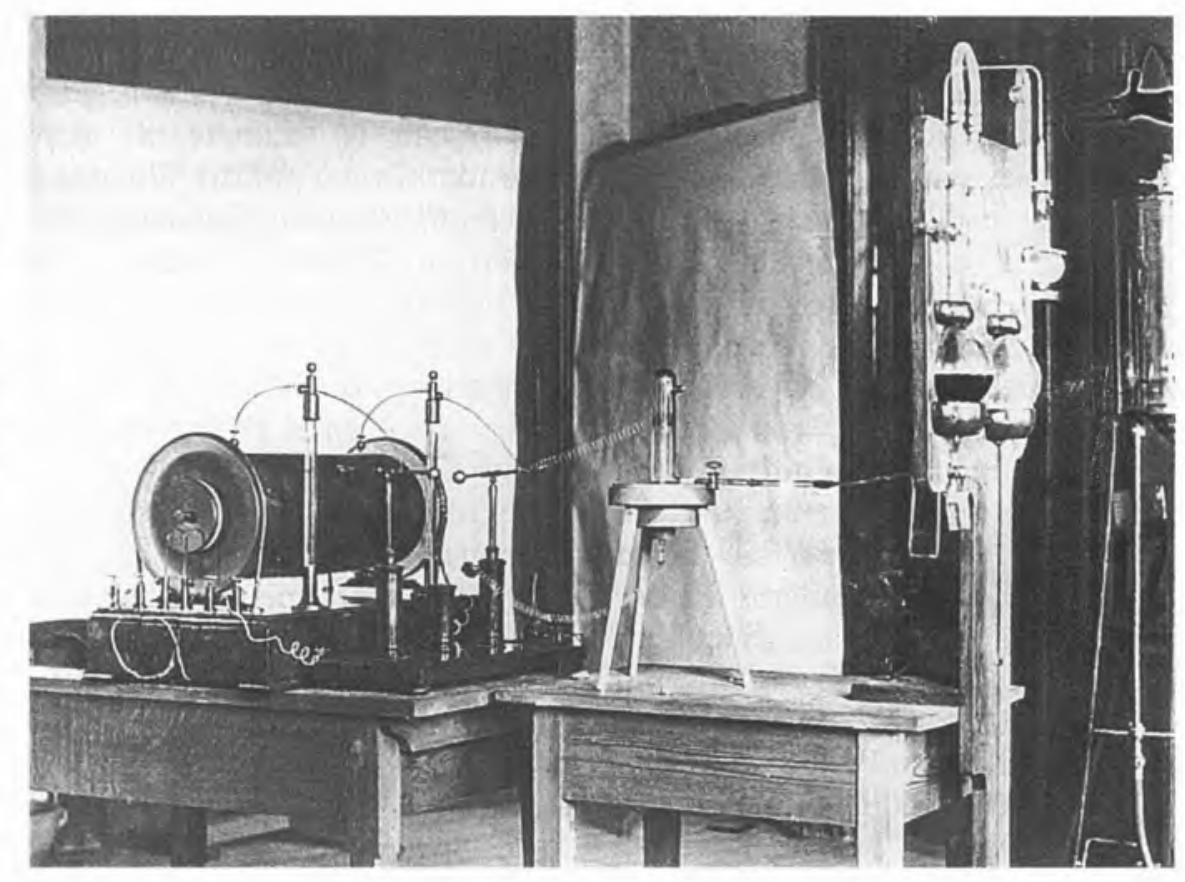

Fig. 1 - Equipamento experimental do laboratório de Röntgen. À esquerda bobina de indução, ao centro tubo de raios catódicos sobre um tripé, à direita bomba difusora de mercúrio.

Die Presse, o qual, segundo uma expressão do próprio Röntgen, fez soar a "trombeta do reclame". O novo tipo de radiação foi descrito em 6 de Janeiro pelo London Daily Cronicle, em 7 de Janeiro pelo Frankfurter Zeitung, em 8 de Janeiro pelo Vossische Zeitung de Berlim, em 13 de Janeiro pelo Le Matin de Paris e em 16 de Janeiro pelo New York Times ${ }^{3}$. No dia 9 de Janeiro, o Imperador Wilhelm I telegrafou a Röntgen para lhe exprimir as maiores felicitações, pedindolhe que proferisse uma conferência sobre a sua descoberta em Berlim. Como representantes do mundo científico, personalidades destacadas tais como Boltzmann, Warburg, Lord Kelvin, Stokes, Poincaré e outros, apresentaram, logo em Janeiro de 1896, reconhecimento por escrito bem como satisfação pela descoberta. A Figura 3 mostra a carta de felicitações de Lord Kelvin. Do mesmo modo, também muitas revistas de Ciências Naturais e de Engenharia informaram de imediato os seus leitores sobre o acontecimento de Würzburg. Assim, por exemplo, o London Electrician relatou a 8 de Janeiro, sob o título "Sensational Worded Story" e o British Journal of Photography, a 10 de Janeiro, com as parangonas "Wonder Camera of the Würzburg Professor". Na revista francesa L'Tllustration apareceu em 17 de Janeiro um artigo sobre a radiação com uma imagem de uma mão irradiada. O texto completo da comunicação preliminar de Röntgen foi publicado pela Nature (Londres) a 16 de Janeiro e pela Science (New York) a 24 de Janeiro.

Os novos raios tiveram, contudo, uma receptividade particularmente entusiástica na Medicina e respectivos meios de comunicação. Logo a 5 e 6 de Janeiro, foram amplamente discutidas em sessões da Sociedade de Medicina e da Sociedade de Medicina Interna, as vantagens dos raios-X para fins de diagnóstico e em traumatologia. No dia 11 de Janeiro, as revistas New York Medical Record, o English Lancet e o British Medical Journal louvaram a descoberta de Röntgen. Para além desses, também o Münchner Medizinische Wochenschrift a 14 de Janeiro, o Wiener klinische Wochenschrift a 16 de Janeiro, as Comptes Rendus (Paris) a 20 de Janeiro, o "Sitzungsbericht der Akade- 


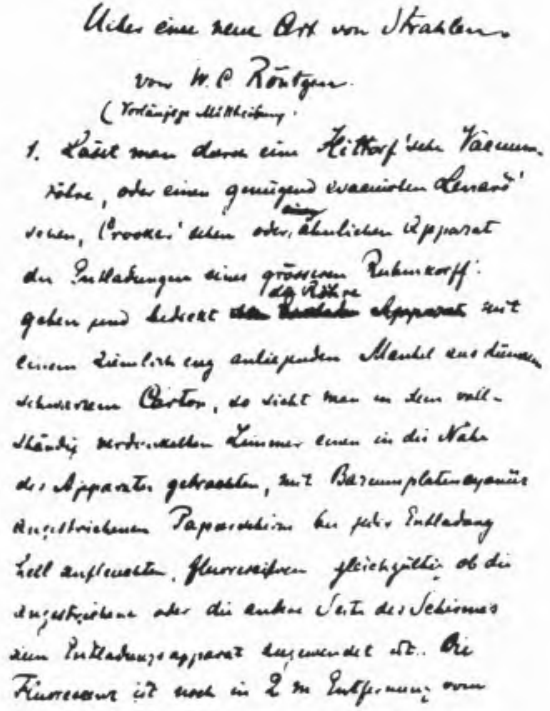

Fig. 2 - Excerto do início da primeira comunicação, manuscrita, de Röntgen.

mischen Wissenschaften Wien" (Actas da Academia das Ciências de Viena) a 23 de Janeiro e a Settimana Medica (Florença) a 25 de Janeiro, escreveram sobre a nova radiação.

O próprio Röntgen proferiu pela primeira vez na tarde de 23 de Janeiro de 1896, perante a Sociedade de Física-Médica de Würtzburg, uma conferência, também aberta ao público, sobre os seus trabalhos ainda "numa fase incipiente". O anatomista A. v. Koelliker, profundamente impressionado pelos trabalhos e pelos ensaios demonstrativos apresentados, propôs a designação futura da radiação-X como raios de Röntgen. No domínio da língua alemã fala-se desde então de "Röntgen Strahlen", enquanto que na utilização da língua inglesa foi conservada a designação "X-rays".

A 31 de Janeiro, H. Muensterberg, Professor de Filosofia da Universidade de Harvard, que então se encontrava na Universidade de Freiburg, relatou detalhadamente na revista Science as inúmeras possibilidades que os raios- $X$ ofereciam para investigações em Medicina. As múltiplas experiências de diagnóstico levadas a cabo na Medicina e as imagens fotográficas assim obtidas, bem

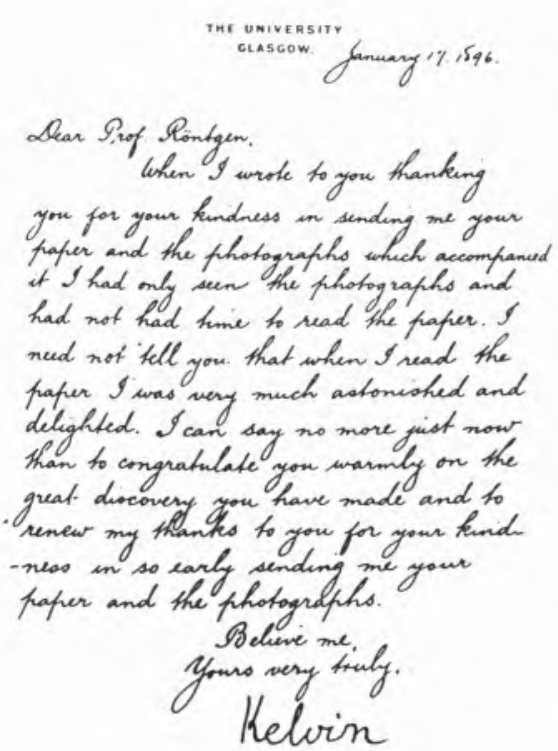

Fig. 3 - Carta de Lord Kelvin a Röntgen.

como as fotografias de ecrans iluminados de partes do corpo humano promoveram, a nível mundial, o interesse do público pelo novo tipo de radiação. Pouco tempo mais tarde, a 18 de Fevereiro, o Journal of the American Medical Association publicou um editorial entusiástico sobre as primeiras experiências com a radiação $X$ de Röntgen, ao qual se seguiram outras comunicações no decorrer desse ano.

Em Fevereiro de 1896 veio a lume a $5^{a}$ edição da primeira comunicação de Röntgen, mencionando a informação de que já se encontrava disponível também em inglês, francês, italiano e russo. Num segundo trabalho, publicado a 9 de Março de 1896 com o título "Um novo tipo de radiação (continuação)" nas Actas da Sociedade de Física-Médica de Würzburg, resumiu Röntgen, nos capítulos 18-21, os resultados das suas investigações adicionais.

A descoberta de Röntgen iniciou uma época que possibilitou às Ciências Naturais sucessos fantásticos e progressos fascinantes nos domínios mais variados. Na Medicina e na maior parte dos seus ramos permitiu explorar possibilidades enormes em diagnóstico e terapia. Em paralelo, foi desenvolvida uma técnica de
raios-X específica que pôs à disposição da Medicina, Ciências Naturais e especialidades tecnológicas, os aparelhos e instalações necessários. Deste modo, o ano de 1995 é duplamente justificado para comemorar Wilhelm Konrad Röntgen, por um lado devido ao $150^{\circ}$ aniversário do seu nascimento e, por outro, pelo $100^{\circ}$ aniversário do dia no qual fez a sua marcante descoberta, a qual, atendendo às suas repercussões, pode ser considerada como uma das maiores proezas da História da Ciência.

\section{* Traduçâo de Maria João Romão, ITQB, Apt, 127-2780 Oeirase IST, Dept.-Quimica, 1096 Lisboa Codex N. da T. - Agradeço à Editora Springer-Verlag a autorização de publicação deste trabalho e de reprodução das figuras. Agradeço a revisão da tradução à Margarida Archer (ITQB).}

\section{NOTAS}

1 Eckard Macherauch: Institut für Werkstoffkunde I, Universi tăt Karlsruhe (TH), Kaiserstr. 12, 76128 Karlsruhe, Alemanha; Hans Neff: Grünberger Str. 17a, 76139 Karlsruhe, Alemanha.

2 Tradução do artigo "Röntgens erste Mitteilungen über eine neue Art von Strahlen" de Eckard Macherauch e Hans Neft, pp.3-5 do livro "Forschung mit Röntgenstrahlen-Bilanz eines Jahrhunderts (1895-1995)", F. H. W. Heuck e E. Macherauch (editores), Springer-Verlag Berlim, Heidelberg, 1995. A editora Springer-Verlag detém os direitos de copyright deste artigo.

${ }^{3}$ N. da T. - Em Portugal, a noticia foi publicada no dia 27 de Janeiro. "Na Universidade de Coimbra, o Dr. Henrique Teixeira Bastos, Professor e Director do Gabinete de Fisica Experimental, no seguimento da notícia do jornal Novidades de 27 de laneiro, realizou as primeiras experiências que tiveram como resultado a obtençăo das primeiras radiografias logo em 2 de Fevereiro" (Alte da Veiga, Os cem anos de raios-X em Portugal, comunicação ao Simpósio -A Radiação $X$ no Desenvolvimento Científico e na Sociedade-, Lisboa 1995.)

\section{BIBLIOGRAFIA}

Glasser O (1959) Wilhelm Conrad Röntgen und die Geschichte der Röntgenstrahlen, 2 Ed. Sprnger, Berlim, Göttingen, Heidelberg.

\section{Muensterberg H (1896) X-rays. Science 3:167}

Röntgen WC (1896) Uber eine neue Art von Strahlen (Vorlàufige Mitteilung). Sitzungsberichte der Würzburger Physicmedic. Gesellshaft.(Actas da Sociedade de Fisica-Médica de W.) $137-141$

Röntgen WC (1896) Eine neue Art von Strahlen (Fortsetzung) Sitzungsberichte der Würzburger Physic-medic. Gesellshaft. (Actas da Sociedade de Física-Médica de Würzburg) 11-19 